\title{
A nanoplex PCR assay for the rapid detection of vancomycin and bifunctional aminoglycoside resistance genes in Enterococcus species \\ Chan Yean Yean ${ }^{1}$, Lee Su Yin², Pattabhiraman Lalitha ${ }^{2}$ and Manickam Ravichandran*1
}

Address: ${ }^{1}$ Department of Medical Microbiology and Parasitology, School of Medical Sciences, Universiti Sains Malaysia, Malaysia and ${ }^{2}$ School of Health Sciences, Universiti Sains Malaysia, Malaysia

Email: Chan Yean Yean - yeancyn@yahoo.com; Lee Su Yin - melysl@hotmail.com; Pattabhiraman Lalitha - lalitha@kb.usm.my; Manickam Ravichandran* - mravic@kb.usm.my

* Corresponding author

Published: II December 2007

BMC Microbiology 2007, 7:1 I2 doi:10.1 I86/I47I-2180-7-II2
Received: 15 May 2007

Accepted: II December 2007

This article is available from: http://www.biomedcentral.com/I47/-2180/7/II2

(c) 2007 Yean et al; licensee BioMed Central Ltd.

This is an Open Access article distributed under the terms of the Creative Commons Attribution License (http://creativecommons.org/licenses/by/2.0), which permits unrestricted use, distribution, and reproduction in any medium, provided the original work is properly cited.

\begin{abstract}
Background: Enterococci have emerged as a significant cause of nosocomial infections in many parts of the world over the last decade. The most common enterococci strains present in clinical isolates are $E$. faecalis and $E$. faecium which have acquired resistant to either gentamicin or vancomycin. The conventional culture test takes $2-5$ days to yield complete information of the organism and its antibiotic sensitivity pattern. Hence our present study was focused on developing a nanoplex PCR assay for the rapid detection of vancomycin and bifunctional aminoglycoside resistant enterococci (V-BiA-RE). This assay simultaneously detects 8 genes namely I6S rRNA of Enterococcus genus, $d d l$ of $E$. faecalis and $E$. faecium, aacA-aphD that encodes high level gentamicin resistance (HLGR), multilevel vancomycin resistant genotypes such as vanA, vanB, vanC and vanD and one internal control gene.
\end{abstract}

Results: Unique and specific primer pairs were designed to amplify the 8 genes. The specificity of the primers was confirmed by DNA sequencing of the nanoplex PCR products and BLAST analysis. The sensitivity and specificity of V-BiA-RE nanoplex PCR assay was evaluated against the conventional culture method. The analytical sensitivity of the assay was found to be I ng at the DNA level while the analytical specificity was evaluated with 43 reference enterococci and nonenterococcal strains and was found to be $100 \%$. The diagnostic accuracy was determined using 159 clinical specimens, which showed that $97 \%$ of the clinical isolates belonged to $E$. faecalis, of which $26 \%$ showed the HLGR genotype, but none were vancomycin resistant. The presence of an internal control in the V-BiA-RE nanoplex PCR assay helped us to rule out false negative cases.

Conclusion: The nanoplex PCR assay is robust and can give results within 4 hours about the 8 genes that are essential for the identification of the most common Enterococcus spp. and their antibiotic sensitivity pattern. The PCR assay developed in this study can be used as an effective surveillance tool to study the prevalence of enterococci and their antibiotic resistance pattern in hospitals and farm animals. 


\section{Background}

Enterococci have emerged as prominent nosocomial pathogens that cause a variety of clinical infections. Enterococcus faecalis and Enterococcus faecium are clinically significant species that are implicated in 90\% and 5-10\% of enterococcal infections, respectively [1].

The widespread use and misuse of antimicrobials such as glycopeptides and aminoglycosides in human and livestock have resulted in the rapid increase of vancomycin and high level gentamicin-resistance in Enterococcus strains [2]. Vancomycin-resistant enterococci (VREs) were first isolated from patients in 1988 in the United Kingdom and France [3]. Since then, VRE have spread to many other countries including Malaysia, in the meat from livestock and by humans [4-7].

Vancomycin resistance in Enterococci have been classified based on the gene sequence and resistance characteristics [8]. The vanA-type strains are resistant to high levels of both vancomycin and teicoplanin antimicrobials (MIC $\geq$ $64 \mu \mathrm{g} / \mathrm{ml}$ and $>16 \mu \mathrm{g} / \mathrm{ml}$, respectively). vanB-type strains are resistant to a wide range of vancomycin concentration (MIC between 4 to $\geq 1,024 \mu \mathrm{g} / \mathrm{ml}$ ) and are susceptible to teicoplanin. vanD-type strains are resistant to moderate levels of vancomycin (MIC $128 \mu \mathrm{g} / \mathrm{mL}$ ) and susceptible to teicoplanin, while $\operatorname{van} \mathrm{C}$, van $\mathrm{E}$, and $\operatorname{van} \mathrm{G}$-type strains exhibit low-level resistance to vancomycin [3,9]. High level gentamicin resistance (HLGR) phenotype is due to the expression of bifunctional aminoglycoside-modifying enzymes $\left[\mathrm{AAC}\left(6^{\prime}\right)-\mathrm{APH}\left(2^{\prime \prime}\right)\right]$ that are encoded by the aacA-aphD gene (Gentamicin MICs range, $\geq 100-500 \mu \mathrm{g} /$ ml) $[10,11]$.

Enterococcal infections are treated with ampicillin only or with a combination of ampicillin and aminoglycoside to achieve synergistic bactericidal activity. However, for patients who are allergic to penicillin or are infected by bacteria with high resistance to ampicillin and aminoglycosides, vancomycin is the powerful, last resort and alternative drug of choice. Intrinsic low-level resistance to aminoglycosides is an inherent property of enterococci. However, the prevalence of high level gentamicin resistance in enterococci is predictive of a loss of synergy between gentamicin and cell wall active agent such as ampicillin or vancomycin [3].

Nucleic acid-based tests using PCR are increasingly being used in laboratories to replace time-consuming, laborintensive and less sensitive conventional diagnostic methods such as biochemical identification and Kirby-Bauer antimicrobial susceptibility tests. Various PCR methods have been developed to identify the (i) Enterococcus genus [12], (ii) vancomycin resistance [13], and (iii) high level aminoglycoside resistance [14]. The above methods do not detect all of the above mentioned targets simultaneously. Hence, the present study was focused to design a nanoplex PCR of vancomycin and bifunctional aminoglycoside resistant enterococci (V-BiA-RE) with an internal control for the detection of (i) Enterococcus genus and clinically important Enterococcus spp., namely E. faecalis and E. faecium, (ii) most common vancomycin resistant genotypes namely van A, B, C, D and (iii) high level gentamicin resistance. In order to rule out false negative results, an internal control was also included in the nanoplex PCR assay.

\section{Results}

In the present study the V-BiA-RE nanoplex PCR was optimized successfully to identify 8 genes of Enterococcus genus, species (E. faecalis and E. faecium), vancomycin resistance (van $\mathrm{A}, \operatorname{van} \mathrm{B}, \operatorname{van} \mathrm{C}$ and $\operatorname{van} \mathrm{D})$ and high level gentamicin resistance (aacA-aphD) simultaneously. Stepwise optimization of primer concentration, annealing temperature, $\mathrm{MgCl}_{2}$, $\mathrm{dNTP}$ and Taq polymerase was done. The V-BiA-RE nanoplex PCR gave the best results when 4 $\mathrm{mM} \mathrm{MgCl} 2,300 \mu \mathrm{M} \mathrm{dNTP,} 2 \mathrm{U}$ Taq polymerase and $65^{\circ} \mathrm{C}$ annealing temperature was used.

The analytical sensitivity of the nanoplex PCR at the DNA level was found to be $1 \mathrm{ng}$ of DNA (data not shown), whereas at the bacterial level it was found to be $10^{5} \mathrm{CFU} /$ $\mathrm{mL}$ (data not shown).

The analytical specificity of the nanoplex PCR assay at the genus level was determined using 13 enterococcal reference strains and found to be positive for the Enterococcus genus specific $16 \mathrm{~S}$ rRNA gene. A representative gel picture of $\mathrm{V}$-BiA-RE with reference strains is shown in Figure 1, while the other 10 Gram-positive and 20 Gram-negative strains were negative. At the species level, all the reference strains of E. faecalis and E. faecium were positive for $d d l$ gene by nanoplex PCR, while other Enterococcus species were negative (Table 1 ). The vancomycin and gentamicin resistant reference strains were positive for $\operatorname{van} \mathrm{A}, \operatorname{van} \mathrm{B}$, van $\mathrm{C}$, van $\mathrm{D}$ or aacA-aph $\mathrm{D}$ genes by nanoplex PCR. However, the vancomycin and gentamicin sensitive reference strains were negative for $\operatorname{van} \mathrm{A}, \operatorname{van} \mathrm{B}, \operatorname{van} \mathrm{C}, \operatorname{van} \mathrm{D}$ or $\operatorname{aac} \mathrm{A}-$ $a p h \mathrm{D}$ genes by nanoplex PCR (Table 1). Overall, the analytical specificity of nanoplex PCR was $100 \%$ for the detection of vancomycin and gentamicin resistant reference strains.

The DNA sequencing results of the PCR amplicon for the 8 genes were contig aligned using the ContigExpress aligment program and were analyzed by BLAST. The results showed that all 8 PCR amplicons were specific to their respective genes and had $91-100 \%$ sequence identity with the existing Genbank sequences. 
Table I: Bacterial species and strains used in this study and results of V-BiA-RE nanoplex PCR.

\begin{tabular}{|c|c|c|c|c|c|c|c|c|c|c|}
\hline No. & Reference strains & I6S rRNA ${ }^{a}$ & ddl-E. faecalis & ddl-E. faecium & $\operatorname{van} A$ & vanB & $\operatorname{vanC}$ & vanD & aacA-aphD & Internal control \\
\hline I. & E. faecium LMG I6004c & + & - & + & + & - & - & - & - & + \\
\hline 2. & E. durans LMG $16172^{c}$ & + & - & - & + & - & - & - & - & + \\
\hline 3. & E. faecium LMG $16192^{c}$ & + & - & + & + & - & - & - & - & + \\
\hline 4. & E. faecalis LMG $8222^{c}$ & + & + & - & - & - & - & - & - & + \\
\hline 5. & E. faecalis LMG $17122^{\circ}$ & + & + & - & - & - & - & - & - & + \\
\hline 6. & E. faecalis LMG $16216^{\mathrm{c}}$ & + & + & - & - & + & - & - & + & + \\
\hline 7. & E. faecium LMG $16200^{\circ}$ & + & - & + & - & - & - & - & - & + \\
\hline 8. & E. raffinosus LMG $12172^{c}$ & + & - & - & - & - & - & - & - & + \\
\hline 9. & E. mundti LMG $12308^{c}$ & + & - & - & - & - & - & - & - & + \\
\hline 10. & E. hirae LMG 6399c & + & - & - & - & - & - & - & - & + \\
\hline 11. & E. avium, LMG I0744c & + & - & - & - & - & - & - & - & + \\
\hline 12. & E. faecium BM 4339 d & + & - & + & - & - & - & + & + & + \\
\hline 13. & E. casseliflavus ${ }^{\mathrm{e}}$ & + & - & - & - & - & + & - & - & + \\
\hline 14. & S. aureus ${ }^{f}$ & - & - & - & - & - & - & - & - & + \\
\hline 15. & Streptococcus spp. Group $A^{f}$ & - & - & - & - & - & - & - & - & + \\
\hline 16. & Streptococcus spp. Group Bf & - & - & - & - & - & - & - & - & + \\
\hline 17. & Streptococcus spp. Group Gf & - & - & - & - & - & - & - & - & + \\
\hline 18. & Streptococcus spp. Group Ff & - & - & - & - & - & - & - & - & + \\
\hline 19. & Bacillus spp. ${ }^{f}$ & - & - & - & - & - & - & - & - & + \\
\hline 20. & Listeria spp. ${ }^{f}$ & - & - & - & - & - & - & - & - & + \\
\hline 21. & Corynebacterium spp. ${ }^{f}$ & - & - & - & - & - & - & - & - & + \\
\hline 22. & Gardnerella spp..$^{f}$ & - & - & - & - & - & - & - & - & + \\
\hline 23. & Lactobacillus spp. ${ }^{f}$ & - & - & - & - & - & - & - & - & + \\
\hline 24. & E. coli $(\mathrm{EHEC})^{\mathrm{f}}$ & - & - & - & - & + & - & - & - & + \\
\hline 25. & E. coli (EPEC) ${ }^{f}$ & - & - & - & - & - & - & - & - & + \\
\hline 26. & E. coli (ETEC) f & - & - & - & - & + & - & - & - & + \\
\hline 27. & V. cholerae (OI classical) ${ }^{f}$ & - & - & - & - & - & - & - & - & + \\
\hline 28. & V. cholerae O139f & - & - & - & - & - & - & - & - & + \\
\hline 29. & V. mimicus ${ }^{f}$ & - & - & - & - & - & - & - & - & + \\
\hline 30. & V. cincinnatiensis ${ }^{f}$ & - & - & - & - & - & - & - & - & + \\
\hline 31. & V. furnissiif & - & - & - & - & - & - & - & - & + \\
\hline 32. & V. parahaemolyticus ${ }^{f}$ & - & - & - & - & - & - & - & - & + \\
\hline 33. & S. typhif & - & - & - & - & - & - & - & - & + \\
\hline 34. & S. sonneif & - & - & - & - & - & - & - & - & + \\
\hline 35. & S. entericaf & - & - & - & - & - & - & - & - & + \\
\hline 36. & S. dysenteriae ${ }^{f}$ & - & - & - & - & - & - & - & - & + \\
\hline 37. & S. boydif & - & - & - & - & - & - & - & - & + \\
\hline 38. & C. freundiff & - & - & - & - & - & - & - & - & + \\
\hline 39. & Y. enterocolitica & - & - & - & - & - & - & - & - & + \\
\hline 40. & P. mirabilis ${ }^{f}$ & - & - & - & - & - & - & - & - & + \\
\hline 41. & P. aeruginosaf & - & - & - & - & - & - & - & - & + \\
\hline 42. & K. pneumoniae ${ }^{f}$ & - & - & - & - & - & - & - & - & + \\
\hline 43. & P. Shigelloides ${ }^{f}$ & - & - & - & - & - & - & - & - & + \\
\hline
\end{tabular}

\section{aEnterococcus genus}

b Bifunctional aminoglycoside resistant genotype

c Reference strains from Belgian Co-ordinated Collections of Micro-organisms (BCCM), Ghent, Belgium

d Kindly provided by Professor. Patrice Courvalin and Dr. Bruno Perichon, Institut Pasteur, Paris, France

e Obtained from Institute for Medical Research, Malaysia

f Department of Medical Microbiology and Parasitology, School of Medical Sciences, Universiti Sains Malaysia. '+' is positive; '-' is negative by V-BiA-

RE PCR

Upon completion of the standardization of the V-BiA-RE nanoplex PCR with reference strains, the assay was validated with 159 clinical isolates. Among the 159 clinical isolates $154(97 \%)$ were found to be E. faecalis and only 5 (3\%) were E. faecium. Of the five E. faecium isolates, four were from blood samples and one was from urine sample. Of the remaining $154 \mathrm{E}$. faecalis isolates, 34 were from blood samples, 59 from urine samples, 42 from pus samples, 6 from high vaginal swab samples, 10 from body fluid samples, 1 from a peritoneum dialysis fluid sample and 2 from urine catheter samples. Thus, the clinical iso- lates had a high percentage of $E$. faecalis infections. However, none of the clinical Enterococcus isolates showed vancomycin resistance.

Among the 159 enterococci isolates, 42 had aacA-aphD gene by V-BiA-Re nanoplex PCR. Of the 42 isolates, 39 were E. faecalis while 3 were E. faecium. However, by the conventional antimicrobial susceptibility method 41 of them were HLGR enterococci (Gentamicin MIC $\geq 100$ $500 \mu \mathrm{g} / \mathrm{mL}$ ). One of the E. faecium isolate that was positive for aacA-aphD gene by nanoplex PCR was found to be 


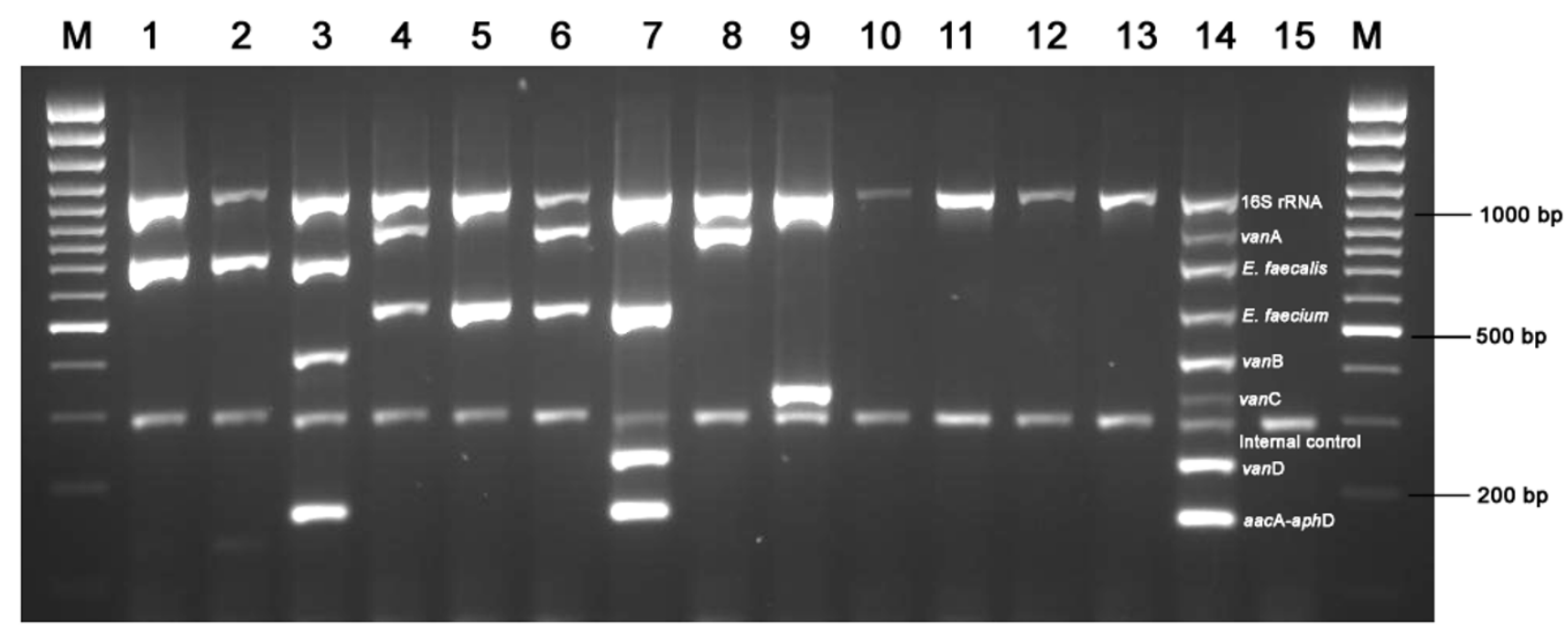

\section{Figure I}

V-BiA-RE nanoplex PCR assay profile with reference strains. M, 100 bp plus marker; Lane I, LMG I7I22 (I6S rRNA and ddl-E. faecalis); lane 2, LMG 8222 (I6S rRNA and ddl-E. faecalis); lane 3, LMG I62 I6 (I6S rRNA, ddl-E. faecalis, vanB and aacA-aphD); lane 4, LMG 16004 (I6S rRNA, ddl-E. faecium and vanA); lane 5, LMG I6200 (I6S rRNA and ddl-E. faecium); lane 6, LMG I6I92 (I6S rRNA, ddl-E. faecium and vanA); lane 7, BM 4339 (I6S rRNA, ddl-E. faecium, vanD and aacA-aphD); lane 8, LMG I6I72 E. durans (I6S rRNA and vanA); lane 9, E. casseliflavus (I6S rRNA and vanC); lane I0, LMG I2I72 E. raffinosus (I6S rRNA); lane I I, LMG I2308 E. mundti (I6S rRNA); lane I2, LMG 6399 E. hirae (I6S rRNA); lane I3, LMG I0744 E. avium (I6S rRNA); lane I4, positive control and lane I5, negative control.

sensitive to gentamicin by conventional MIC method. Though genotypically the aacA-aphD gene was detected and confirmed by PCR and sequencing, it is possible that the $a a c \mathrm{~A}-a p h \mathrm{D}$ gene is non-functional and is not expressed phenotypically or due to the presence of pseudogene [15].

The diagnostic accuracy of V-BiA-RE nanoplex PCR at the genus and species level was determined using 159 clinical isolates and found to have $100 \%$ sensitivity, specificity, positive and negative predictive values. However, the VBiA-RE nanoplex PCR for the aacA-aphD gene detection showed $97.7 \%$ sensitivity, $100 \%$ specificity, $100 \%$ positive and $99.4 \%$ negative predictive values in detecting HLGR enterococci.

\section{Discussion}

The present study is unique since it is the first study where we have developed a combined molecular test for the determination of the Enterococcus genus, two clinically important species (E. faecalis and E. faecium) and vanA-D genotypes and high level gentamicin resistance (HLGR) simultaneously. Currently the available assay is able to detect either gentamicin or vancomycin resistance [1013]. Though there are numerous reports on PCR assays for the detection of VREs $[13,16]$, only few of them have incorporated internal controls in their assays to rule out false negatives $[17,18]$. According to CLSI guidelines for
Molecular Diagnostic Methods for Infectious Diseases (MM3-A2), incorporation of an internal control in the reaction is essential for the diagnostic test to exclude false negative result or the presence of inhibitors [19]. In the present study, the inclusion of the $300 \mathrm{bp}$ internal control in the V-BiA-RE nanoplex PCR assay helped us to rule out false negatives or PCR inhibitors.

The V-BiA-RE nanoplex PCR was found to be 100\% sensitive and specific in detecting known vancomycin and gentamicin resistance genes in Enterococcal strains. The use of V-BiA-RE PCR as a diagnostic tool was also studied by analyzing 159 clinical isolates obtained from 3 different hospitals in Malaysia. We found that most of them were E. faecalis (94\%) and all of them were susceptible to vancomycin. However, 26\% were resistant to HLGR. These results are consistent with results of other groups, where they have shown that E. faecalis is predominant among the clinical isolates and were vancomycin sensitive though some were HLGR enterococci $[3,14]$.

In Malaysia the presence of VREs has been reported from clinical [5-7] and farm animal samples [16,20]. Sporadic cases of VRE infection and colonization have also been reported in the neighboring country, Singapore [4]. Since antimicrobial-resistant enterococci have been detected in livestock in Malaysia, there could be a possible epidemio- 
logical link between livestock origin and human infections $[4-7,16,20]$. Hence, characterization of VRE isolates from human stools and livestock animals is needed, especially in areas where antibiotics can be obtained from any drug store or over-the-counter and where farmers feed their chickens with antibiotics to promote growth $[3,15]$.

The percentage of HLGR enterococci observed in this study $(26 \%)$ is relatively lower than those reported in China (64\%) [10] and Greece (42\%) [11]. In both studies, the HLGR enterococci were mostly associated with the presence of aacA-aphD gene as observed in this study.

Genomic DNA extracted from two of the E. coli (EHEC and ETEC) strains found to have van $\mathrm{B}$ gene like products (Table 1). It has been documented that the E. coli possess homologous genes called $d d l \mathrm{~A}$ and $d d l \mathrm{~B}$ [GenBank accession: $\underline{\underline{000096}}$ ] that have $29-38 \%$ amino acid identity to van $\mathrm{A}$ and $\operatorname{van} \mathrm{C}$ genes [21]. However sequencing of these PCR product revealed that it is similar to a hypothetical protein present in E. coli (Gene-Ecs5269, GenBank accession number BA000007) and is not related to $d d l \mathrm{~A} / d d l \mathrm{~B}$ genes of $E$. coli. It is possible that in the nanoplex PCR assay, the presence of 9 pairs of primers might have lead to non-specific PCR product. These types of false positive results do not arise when Enterococci broth is used as an enrichment medium, since this medium is known to inhibit Gram-negative bacterial (E. coli) growth.

The limitations of the conventional antimicrobial susceptibility tests are that the susceptibility pattern varies with inoculum size. In addition, there is no standardized MIC cut-off value available for $\operatorname{van} \mathrm{A}, \operatorname{van} \mathrm{B}, \operatorname{van} \mathrm{C} 1 / \mathrm{C} 2 / \mathrm{C} 3$ and van $\mathrm{D}$ in conventional antimicrobial susceptibility tests. Currently, it is not a usual practice in laboratories to identify the species of Enterococcus, except in cases of septicemia. Genotype-based molecular tests can overcome the limitation, where the presence of the gene is accurately detected when the CFUs of the bacteria are more than the analytical sensitivity level. Moreover, rapid detection of antibiotic resistant bacteria is important not only for therapeutic decisions, but also for infection control [15].

The $\operatorname{van} \mathrm{E}$ and $\operatorname{van} \mathrm{G}$ primers were not included in the $\mathrm{V}$ BiA-RE nanoplex PCR since these genotypes are not common among Enterococcus spp. [22]. The V-BiA-RE nanoplex PCR assay developed in the present study will be useful in the epidemiological screening of VRE carriers or reservoirs. We are currently evaluating this assay for screening VRE carriage in human stools and poultry farms in Malaysia.

\section{Conclusion}

Bacterial lysates prepared by a simple boiling method without lysis buffer and lytic enzymes were used as tem- plates in the V-BiA-RE nanoplex PCR assay. The PCR assay was able to detect 8 genes that are essential for the identification of the most common enterococci spp. and their vancomycin and gentamicin resistance genotypes simultaneously in a single test within 4 hours. The built-in internal control in this assay prevents the false negative cases. The diagnostic accuracy was determined using the 159 clinical specimens which showed $97 \%$ of the clinical isolates belonged to E. faecalis, of which $26 \%$ showed HLGR genotype, but none were vancomycin resistant. Hence, this test can be used as an effective diagnostic and surveillance tool to monitor the spread and emergence of VRE.

\section{Methods Study design}

This is a retrospective diagnostic study where the sample size was calculated by single proportion test based on the prevalence of $12.3 \%$ [23] and 95\% Confidence Interval with expected specificity of $92 \%$. The study was approved by the Research and Ethics Committee, School of Medical Sciences, Universiti Sains Malaysia.

\section{Bacterial strains and clinical specimens}

The reference Enterococcus spp. and other bacteria used in this study are listed in Table 1. A total of 159 Enterococcus spp. isolated from routine clinical specimens obtained from three hospitals namely, Hospital Universiti Sains Malaysia (HUSM), General Hospital Kota Bharu (GHKB) and Hospital Tengku Ampuan Afzan, Kuantan, Malaysia from May to October 2004 were used in this study. Of these 159 isolates, 38 were isolated from blood samples, 60 from urine samples, 42 from pus samples, 6 from high vaginal swabs, 10 from body fluid samples, 1 from peritoneum dialysis fluid and 2 from urine catheter samples.

\section{Screening of Enterococcus spp. from clinical specimens by conventional method}

The clinical isolates were inoculated into Enterococci broth (Merck, Darmstadt, Germany) and Enterococcosel agar [Becton Dickinson (BD), BBL, New Jersey, USA] without the addition of vancomycin and incubated at $37^{\circ} \mathrm{C}$ for 24 hours. The isolates that showed growth in both media were selected for biochemical identification and antimicrobial susceptibility testing.

To differentiate Enterococcus from other Group D streptococci, isolated colonies from clinical specimens were tested by standard biochemical tests (PYR: Oxoid, United Kingdom, England; Enterococcosel agar: BD, BBL, New Jersey, USA and $6.5 \% \mathrm{NaCl}$ brain heart infusion (BHI) broth: Oxoid, United Kingdom, England). Further confirmation to the species level was carried out as described by Facklam and Waitkins [24,25]. The reference strains E. raffinosus (LMG 12172) and E. durans (LMG16172) (Belgian Co-ordinated Collections of Micro-organisms, 
BCCM, Ghent, Belgium) were used as controls for the above biochemical tests.

Minimum inhibitory concentration (MIC) of vancomycin (CheilJedang, Korea), teicoplanin (Gruppo Lepetit, Italy) and gentamicin (Duopharma, Malaysia) was determined by agar dilution method according to CLSI (Clinical and Laboratory Standards Institute) guidelines with slight modification based on the procedures as described by Hayes et al.[26]. Furthermore, E-test kits (AB Biodisk, Solna, Sweden) were also used to determine the susceptibility patterns of vancomycin. The results were categorized according to CLSI standards. Reference strains used as controls were E. faecium (LMG 16192), E. faecalis (LMG 16216), E. faecium (BM 4339) and E. casseliflavus (Table 1).

\section{Primer designing for V-BiA-RE nanoplex PCR}

The 16S rRNA of Enterococcus genus, ddl of E. faecium, ddl of $E$. faecalis, $\operatorname{van} \mathrm{A}, \operatorname{van} \mathrm{B}, \operatorname{van} \mathrm{C}, \operatorname{van} \mathrm{D}$, and $a a c \mathrm{~A}-a p h \mathrm{D}$ gene sequences were obtained from GenBank [27] for DNA sequence alignment and primer design. The ClustalW program in Vector NTI version 9.0 software (Invitrogen Corporation, California, USA) was used to align the DNA sequences. The conserved and non-conserved regions of the DNA sequence alignments were visualized using GeneDoc software [28]. Based on the conserved regions of the alignment, specific primer pairs were designed to amplify the Enterococcus genus. Specific primers of E. faecium and E. faecalis species were designed based on the non-conserved regions of $d d l$ gene sequences. Vancomycin resistance specific primers were designed based on the non-conserved regions of $\operatorname{van} \mathrm{A}, \operatorname{van} \mathrm{B}, \operatorname{van} \mathrm{C}$, and $\operatorname{van} \mathrm{D}$
DNA sequences. High level gentamicin resistance (HLGR) specific primers were designed based on aacA-aphD gene. The 8 primer pairs were designed in such a way that the PCR products ranged from $150 \mathrm{bp}$ to $1200 \mathrm{bp}$. The specificity of the designed primers was checked using BLAST available at the GenBank website [29]. The primer sequences for the 8 genes and expected PCR product sizes are shown in Table 2. A primer pair based on ctxA gene was designed and was used as an internal control.

\section{V-BiA-RE nanoplex PCR assay}

The monoplex PCR for each gene and the V-BiA-RE nanoplex PCR assays were standardized using genomic DNA extracted from reference Enterococcus spp. A mixture of DNAs from 4 reference strains namely E. faecium (LMG 16192), E. faecalis (LMG 16216), E. faecium (BM 4339) and $E$. casseliflavus that contained the 8 genes of interest was used as a positive control. DNase-free distilled water was used as a negative control. In addition, a plasmid containing ctxA gene ( $1 \mathrm{pg}$ ) was used as a template for the internal control. To rule out false negative activities, an internal control (primers pair and template) was incorporated in every reaction mixture including negative controls.

The diagnostic evaluation of the nanoplex PCR was done using the lysates from 159 clinical isolates. The isolated colonies from Enterococcosel agar were inoculated into $\mathrm{LB}$ broth and incubated at $37^{\circ} \mathrm{C}$ for 24 hours. Bacterial lysates for PCR were prepared by centrifuging the $100 \mu \mathrm{l}$ of culture at $10,000 \times g$ for 3 minutes, the supernatant were removed and the pellets were resuspended in $100 \mu \mathrm{l}$ of DNase-free distilled water. The suspensions were

Table 2: Sequences of primers used for the V-BiA-RE nanoplex PCR.

\begin{tabular}{|c|c|c|c|c|}
\hline Gene & Primer Name & 5'--------------------------------3' & GenBank Accession Number & Product Size \\
\hline \multirow[t]{2}{*}{ I 6S rRNA } & I6SrRNA-F & AGG GGA TAA CAC TTG GAA ACA & $\mathrm{AB} 015233$ & 1178 bp \\
\hline & I6SrRNA-R & TTC GCG ACT CGT TG TAC TTC & & \\
\hline \multirow[t]{2}{*}{ ddI E. faecalis } & Elis-F2 & GGC CCT CTT TTA TCT GAA CGA & $\underline{U} 00457$ & 734 bp \\
\hline & Elis-R3 & GCG ACT TAA GCC ACT TCC AT & & \\
\hline \multirow{2}{*}{ ddl E. faecium } & Ecium-F & CGC AGA GCA TGA AGT GTC CA & $\underline{\text { AF550665 }}$ & $557 \mathrm{bp}$ \\
\hline & Ecium-R2 & CTT CTC GGT TTT CTG CTT TTG TA & & \\
\hline \multirow[t]{2}{*}{ VanA } & $\operatorname{van} A-F$ & TTG GGG GTT GCT CAG AGG AG & $\underline{\times 56895}$ & $931 \mathrm{bp}$ \\
\hline & $\operatorname{vanA-R}$ & CTT CGT TCA GTA CAA TGC GG & & \\
\hline \multirow[t]{2}{*}{ VanB } & vanB-F & AAT GCG GGG AGG ATG GTG CG & AF550667 & 446 bp \\
\hline & vanB-R & GAT GCG GAA GAT ACC GTG GC & & \\
\hline \multirow[t]{2}{*}{ VanC } & vanC-F2 & GCA GGT TCT GCC TTA TGT ATG AA & AFI62694, AY033764, L29638 & $339 \mathrm{bp}$ \\
\hline & $\operatorname{vanC-R}$ & ATG AAA TGG CGT CAC AAG CA & & \\
\hline \multirow[t]{2}{*}{ VanD } & vanD-F & CGT ATG TGG GAT GCG ATA TTC AA & $\mathrm{AFI} 30997$ & $230 \mathrm{bp}$ \\
\hline & vanD-R2 & CTT CGA TTG CTG CCT GCA GTT & & \\
\hline \multirow[t]{2}{*}{ aacA-aphD } & acph-FIL & GAT TTG CCA GAA CAT GAA TTA CAC GA & AY 602207 & $156 \mathrm{bp}$ \\
\hline & acph-RIL & CAT AAC CAC TAC CGA TTA TTT CAA T & & \\
\hline \multirow[t]{2}{*}{ Internal Control (ctxA) } & IC-F & AAC TCA GAC GGG ATT TGT TAG GC & AF510996 & $300 \mathrm{bp}$ \\
\hline & IC-R & TCT CTG TAG CCC CTA TTA CGA TGT & & \\
\hline
\end{tabular}


boiled in a water bath for 10 minutes and centrifuged again at $10,000 \times g$ for 3 minutes. Then, $2 \mu \mathrm{l}$ of the supernatants (lysates) were used in the V-BiA-RE nanoplex PCR assays.

The optimized concentration of primer for each gene $(0.2$ pmol 16S rRNA, 0.8 pmol ddl-E. faecium, $0.8 \mathrm{pmol} d d l-E$. faecalis, $0.8 \mathrm{pmol}$ van $\mathrm{A}, 0.05 \mathrm{pmol} \operatorname{van} \mathrm{B}, 0.7 \mathrm{pmol} \operatorname{van} \mathrm{C}$, $0.4 \mathrm{pmol} v a n \mathrm{D}, 1 \mathrm{pmol} a a c \mathrm{~A}-a p h \mathrm{D}$ and $0.2 \mathrm{pmol} \operatorname{ctx} \mathrm{A}$ ) was used in the V-BiA-RE nanoplex PCR. The other components used in the PCR were $300 \mu \mathrm{M}$ dNTPs, $4 \mathrm{mM} \mathrm{MgCl}_{2}$, $1 \times$ PCR buffer and $2 \mathrm{U}$ Taq DNA polymerase (Fermentas, Vilnius, Lithuania). The PCR was carried out using a Mastercycler Gradient (Eppendorf, Hamburg, Germany) with one cycle of initial denaturation at $95^{\circ} \mathrm{C}$ for $5 \mathrm{~min}, 30$ cycles of denaturation at $95^{\circ} \mathrm{C}$ for $30 \mathrm{sec}$, annealing for 30 sec at $65^{\circ} \mathrm{C}$ and extension at $72^{\circ} \mathrm{C}$ for $30 \mathrm{sec}$, followed by an extra cycle of annealing at $65^{\circ} \mathrm{C}$ for $30 \mathrm{sec}$ and a final extension at $72^{\circ} \mathrm{C}$ for $5 \mathrm{~min}$. The PCR products were analyzed by electrophoresis on 2\% low EEO agarose gels (Promega, Madison, USA) with ethidium bromide at 90 Volts for 75-90 min. PCR products were visualized under UV illumination and photographed using an image analyzer (ChemiImager 5500, Alpha Innotech, California, USA).

\section{Confirmation of the PCR amplicons by DNA sequencing}

All eight PCR products of the different genes that were obtained from reference strains (Table 1) were cloned into a PCR cloning vector pTZ57T/R (Fermentas, Vilnius, Lithuania) and sequenced using an automated DNA sequencer at Tech Dragon Ltd (Hong Kong, China). The DNA sequencing results were analyzed using the ContigExpress alignment program in Vector NTI version 9.0 software (Invitrogen corporation, California, USA). Resultant contigs were analyzed by BLAST [29] provided by the National Center for Biotechnology Information to calculate the percentage identity.

\section{Evaluation of V-BiA-RE nanoplex PCR assay}

Analytical specificity was evaluated using DNA lysates prepared from pure cultures of 13 phenotypically and genotypically well-characterized Enterococcus spp. and 10 Gram-positive and 20 Gram-negative strains obtained from different sources (Table 1).

The analytical sensitivity was evaluated using various concentrations of genomic DNA starting from $1 \mu \mathrm{g}$ to $10 \mathrm{pg}$ and lysate starting from $10^{8}-10^{3} \mathrm{CFU} / \mathrm{ml}$ obtained from a reference strain, E. faecalis (LMG 16216).

The diagnostic evaluation of the nanoplex PCR was carried out using 159 clinical isolates. The results were compared with the conventional microbiological, biochemical, and antimicrobial susceptibility tests which were considered as the 'gold standard' [30].

\section{Statistical analysis}

The clinical sensitivity, specificity, positive $\left(\mathrm{PV}^{+}\right)$and negative predictive value (PV-) of V-BiA-RE nanoplex PCR were calculated based on the CLSI Guidelines for Molecular Diagnostic Methods for Infectious Diseases [30].

\section{Authors' contributions}

CYY carried out the DNA sequence alignment, designed the primers, developed multiplex PCR, analyzed clinical samples and helped to draft the manuscript. LSY contributed in the multiplex PCR optimization, sample analysis and was involved in drafting of the manuscript. PL participated in the study design, primer design, data analysis and critically edited and revised the manuscript. MR conceived and coordinated the study, helped in DNA sequence analysis and primer design, data analysis and drafted the manuscript. All authors read and approved the final manuscript.

\section{Acknowledgements}

This work was funded by the IRPA Top down Project 06-02-03-2065 PR0047//9-1I of the Ministry of Science Technology and Innovation (MOSTI), Malaysia. We are grateful to Dr. Mukarramah C. Ayub from the Department of Pathology, General Hospital Kota Bharu, Kelantan, Malaysia; and Mr. Alex Francis from Hospital Tengku Ampuan Afzan, Kuantan, Malaysia; for providing the clinical isolates. We would like to thank the Institute for Research in Molecular Medicine (INFORMM), Universiti Sains Malaysia (USM), Malaysia for providing the research infrastructure and Dr. Salimah from the Biostatistics unit, School of Medical Sciences, USM for statistical consultation.

\section{References}

I. Simonsen GS, Smabrekke L, Monnet DL, Sorensen TL, Moller JK, Kristinsson KG, Lagerqvist-Widh A, Torell E, Digranes A, Harthug S, Sundsfjord A: Prevalence of resistance to ampicillin, gentamicin and vancomycin in Enterococcus faecalis and Enterococcus faecium isolates from clinical specimens and use of antimicrobials in five Nordic hospitals. J Antimicrob Chemother 2003, 5 I (2):323-331.

2. Phillips I, Casewell M, Cox T, De Groot B, Friis C, Jones R, Nightingale $C$, Preston R, Waddell J: Does the use of antibiotics in food animals pose a risk to human health? A critical review of published data. J Antimicrob Chemother 2004, 53(I):28-52.

3. Cetinkaya Y, Falk P, Mayhall CG: Vancomycin-resistant enterococci. Clin Microbiol Rev 2000, I3(4):686-707.

4. Fisher DA, Lin R, Chai L, Kumarasinghe G, Singh K, Tambyah PA: Vancomycin-resistant enterococci in a Singapore teaching hospital prior to 2005. Singapore Med J 2005, 46(6):3 I I-3I 2.

5. Raja NS, Karunakaran R, Ngeow YF, Awang R: Communityacquired vancomycin-resistant Enterococcus faecium: a case report from Malaysia. J Med Microbiol 2005, 54(Pt 9):90।-903.

6. Riley PA, Parasakthi N, Teh A: Enterococcus faecium with highlevel vancomycin resistance isolated from the blood culture of a bone marrow transplant patient in Malaysia. Med J Malaysia 1996, $51: 383-385$.

7. Zubaidah AW, Ariza A, Azmi S: Hospital-acquired vancomycinresistant enterococci: now appearing in Kuala Lumpur Hospital. Med J Malaysia 2006, 6 I (4):487-489.

8. Vancomycin-resistant Enterococci (VRE) and the Clinical Laboratory [http://www.cdc.gov/ncidod/dhqp/ar lab vre.html] 
9. Depardieu F, Bonora MG, Reynolds PE, Courvalin P: The vanG glycopeptide resistance operon from Enterococcus faecalis revisited. Mol Microbiol 2003, 50(3):931-948.

10. Qu TT, Chen YG, Yu YS, Wei ZQ, Zhou ZH, Li LJ: Genotypic diversity and epidemiology of high-level gentamicin resistant Enterococcus in a Chinese hospital. J Infect 2006, 52(2): $124-130$.

II. Tsakris A, Pournaras S, Maniatis AN, Douboyas J, Antoniadis A: Increasing prevalence of high-level gentamicin resistance among Enterococci isolated in Greece. Chemotherapy 200I, 47(2):86-89.

12. Jackson CR, Fedorka-Cray PJ, Barrett JB: Use of a genus- and species-specific multiplex PCR for identification of enterococci. J Clin Microbiol 2004, 42(8):3558-3565.

13. Depardieu F, Perichon B, Courvalin P: Detection of the van alphabet and identification of enterococci and staphylococci at the species level by multiplex PCR. J Clin Microbiol 2004, 42( I 2):5857-5860.

14. Vakulenko SB, Donabedian SM, Voskresenskiy AM, Zervos MJ, Lerner SA, Chow JW: Multiplex PCR for detection of aminoglycoside resistance genes in enterococci. Antimicrob Agents Chemother 2003, 47(4): I $423-1426$.

15. Sundsfjord A, Simonsen GS, Haldorsen BC, Haaheim H, Hjelmevoll SO, Littauer P, Dahl KH: Genetic methods for detection of antimicrobial resistance. Apmis 2004, I I 2(I I- | 2):8 I5-837.

16. Radu S, Toosa H, Rahim RA, Reezal A, Ahmad M, Hamid AN, Rusul $G$, Nishibuchi M: Occurrence of the vanA and van $C 2 / C 3$ genes in Enterococcus species isolated from poultry sources in Malaysia. Diagn Microbiol Infect Dis 200I, 39(3): I45-I53.

17. Sloan LM, Uhl JR, Vetter EA, Schleck CD, Harmsen WS, Manahan J, Thompson RL, Rosenblatt JE, Cockerill FR 3rd: Comparison of the Roche LightCycler vanA/vanB detection assay and culture for detection of vancomycin-resistant enterococci from perianal swabs. I Clin Microbiol 2004, 42(6):2636-2643.

18. Sahm DF, Free L, Smith C, Eveland M, Mundy LM: Rapid characterization schemes for surveillance isolates of vancomycinresistant enterococci. J Clin Microbiol 1997, 35(8):2026-2030.

19. Nolte FS JCA, Cockerill FR, Dailey PJ, Hillyard D, McDonough S, Meyer RF, Shively RG: Molecular Diagnostic Methods for Infectious Diseases; Approved Guideline. 2nd edition. 2006, 26:73.

20. Ong CH, Asaad M, Lim KC, Ngeow YF: Infrequent occurrence of vancomycin-resistant enterococci in poultry from Malaysian wet markets. Malays J Pathol 2002, 24(2):91-94.

21. Dutka-Malen S, Molinas C, Arthur M, Courvalin P: Sequence of the vanC gene of Enterococcus gallinarum BM4I74 encoding a D-alanine:D-alanine ligase-related protein necessary for vancomycin resistance. Gene 1992, I / 2(I):53-58.

22. Domingo MC, Huletsky A, Giroux R, Boissinot K, Picard F], Lebel P, Ferraro MJ, Bergeron MG: High prevalence of glycopeptide resistance genes van $B$, vanD, and vanG not associated with enterococci in human fecal flora. Antimicrob Agents Chemother 2005, 49(II):4784-4786.

23. Oon LL, Ling MM, Chiew YF: Gastrointestinal colonisation of vancomycin-resistant enterococcus in a Singapore teaching hospital. Pathology 200I, 33(2):216-22I.

24. Facklam R, Hollis D, Collins MD: Identification of gram-positive coccal and coccobacillary vancomycin-resistant bacteria. J Clin Microbiol 1989, 27(4):724-730.

25. Waitkins SA, Ball LC, Fraser CA: A shortened scheme for the identification of indifferent streptococci. J Clin Pathol 1980, 33(I):47-52

26. Hayes JR, English LL, Carr LE, Wagner DD, Joseph SW: Multipleantibiotic resistance of Enterococcus spp. isolated from commercial poultry production environments. Appl Environ Microbiol 2004, 70(10):6005-60I I.

27. GenBank [http://www.ncbi.nlm.nih.gov/Genbank/]

28. GeneDoc [http://www.nrbsc.org/downloads/]

29. GenBank BLAST search [http://www.ncbi.nlm.nih.gov/BLAST/]

30. Molecular Diagnostic Methods for Infectious Diseases; Approved Guideline (CLSI MM3-A2). 2nd edition. 2006, 26:73.

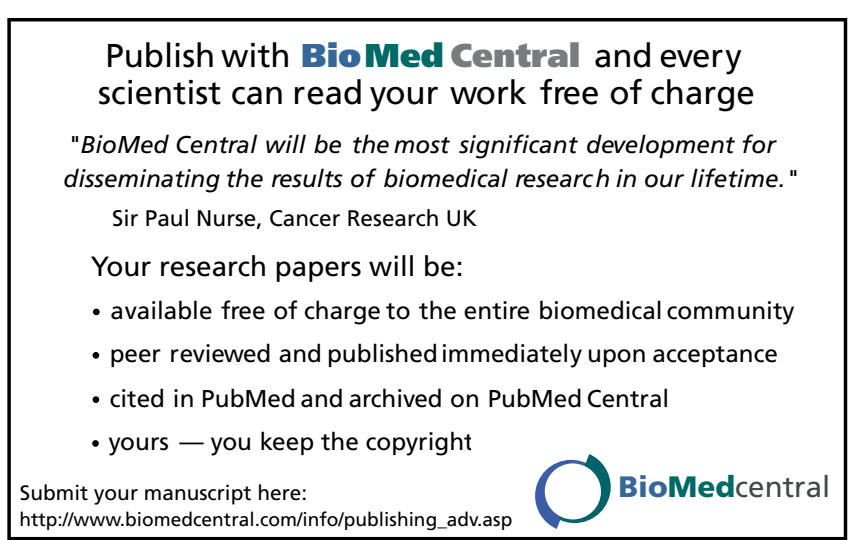

